\title{
Les Bons Mots: Wisdom in Words for CMP and Millennial Medical Anthropology
}

\author{
Atwood D. Gaines ${ }^{1}$
}

Published online: 24 February 2018

(C) Springer Science+Business Media, LLC, part of Springer Nature 2018

The Quotes of the Volume have appeared in Culture, Medicine and Psychiatry since 2009. The quotes were intended as part of the pedagogical enterprise of that journal. They are presented here to regain and disseminate the wisdom contained in the quotes, all of which, as well as the words of other scholars, are key elements of the foundation of Millennial Medical Anthropology (MMA) (Gaines 2010), a Medical Anthropology that culturally studies (bio)Science, and Medicines alike in the Cultural Studies of Science and Medicine (CSSM) and integrates Cultural Bioethics, Medical Humanities, Histories and Philosophies of Medicine with the interpretive forms of Medical Anthropology. The goal is synthesis, not 'interdisciplinarity'.

Each of the quotes below could generated volumes in response and commentary. However, here only a brief statement is provided following the individual quotes. One should note the variety of fields represented, a variety which serves three purposes; to provide key and foundational philosophical statements of CMP, the same for Millennial Medical Anthropology (MMA) and, finally, to demonstrate the synthesis suggested by both.

Toward this end, powerful statements were presented to point directly to the bases of MMA and away from the usual functionalist, causalist, materialist medical social sciences and medicines. The first quote, from 2009, therefore, came from E.E. Evans-Pritchard, the noted British social anthropologist. His short statement, in fact,

\footnotetext{
The Quotes of the Volume have appeared in Culture, Medicine and Psychiatry since 2009. The quotes were intended as part of the philosophy and pedagogical enterprise of the journal. However, this exercise was lost to all those save print copy recipients as the publication portal of the Journal did not consider these quotes as 'entities' that could be read online and downloaded.
}

Atwood D. Gaines

atwood.gaines@case.edu

1 Case Western Reserve University, Cleveland, USA 
lays the foundation for a new form of social science altogether, the interpretive turn (Rabinow and Sullivan 1979) and serves as its charter. And, we note his argument that history and anthropology were kindred disciplines.

Quote of the Volume

Volume 33: 2009

Colleagues in Social Anthropology, "would prefer to describe what (they) do in the language of the methodology of the natural sciences, whereas what I have said implies that Social Anthropology studies societies as moral, or symbolic, systems and not as natural systems, that it is less interested in process than in design, and that it therefore, seeks patterns and not laws, demonstrates consistency and not necessary relations between social activities, and interprets rather than explains. These are conceptual, and not merely verbal, differences" (p. 62).

\section{E.E. Evans-Pritchard}

Later Theoretical Developments. In Social Anthropology and Other Essays. Glencoe, IL: The Free Press. 1962. (original 1948).

$\mathrm{E}-\mathrm{P}$, as he is known, came to the key discernment of millennial medical anthropology in the 1940's, in a statement originally broadcast on the BBC and in which he sought to disassociate himself from Radcliffe-Brown's structural functionalism, i.e., that societies are not natural systems, as Radcliffe-Brown thought, but rather, they are moral systems.

This statement, of course, summarizes much of Clifford Geertz's work (but not his earliest ecological and economic studies). As moral systems, we cannot use the notions of social or other laws as 'explanations' of human phenomena. Social systems as moral systems are thus human creations in 'local moral worlds' to use one of Kleinman's phrases. Such systems are to be understood and cannot be explained as in the nineteenth century model of social science fashioned on a mistaken analogy with the natural sciences.

Quote of the Volume

Volume 34: 2010

...creative writers are valuable allies and the evidence is to be prized highly, for they are apt to know of a whole host of things between heaven and earth of which our philosophy has not yet let us dream. In their knowledge of the mind they are far in advance of us everyday people. (p. 8)

\section{Sigmund Freud}

Delusion and Dream in Jensen's Gradiva. In The Interpretation of Dreams. The Standard Edition of the Complete Works of Sigmund Freud, translated by James Strachey. London, 1962, Vol. IX.)

After Evans-Pritchard's key orienting statement, that is central to the mission of the Journal, Culture, Medicine and Psychiatry since 2007, we find Freud himself 
making an argument for medical humanities in the 2010 quotation from his Collected Works.

While a neurologist who thought that one day researchers would find material bases for psychic structures and processes, which, of course, they have not and are not going to, Freud understood that interpretation and understanding where the order of the day and that, what we call today, medical humanities, would be suited for the task.

Quote of the Volume

Volume 35: 2011

Concerning the prevailing view of psychoanalytic theory in the pre-1980s feminist movement: "Psychoanalysis is seen as a justification for the statusquo, bourgeois and patriarchal, and Freud in his own person exemplifies these qualities. I would agree that popularized Freudianism must answer to this description; but the argument of this book is that a rejection of psychoanalysis and Freud's works is fatal for feminism. However it may have been used, psychoanalysis is not a recommendation for a patriarchal society, but (rather) an analysis of one (p. xiii)

\section{Juliet Mitchell}

Psychoanalysis and Feminism: Freud, Reich, Laing and Women. New York: Vintage Books. 1975.

In the 2011 quote, noted British philosopher of science and feminist, Juliet Mitchell points out that the interpretative system of Freud, psychoanalysis, was not itself a "recommendation for a patriarchal society, but (rather) an analysis of one". (1975:xii). And she distinguishes between psychoanalysis and popularized versions of it that are bourgeois and patriarchal. Mitchell's perspective revivifies psychoanalytic theory as a salient interpretive system for feminism and social science beyond.

\section{Quote of the Volume}

Volume 36: 2012

Culture is public because meaning is. You can't wink (or burlesque one) without knowing what counts as winking or how, physically, to contract your eyelids, and you can't conduct a sheep raid (or mimic one) without knowing what it is to steal a sheep and how practically to go about it. But to draw from such truths the conclusion that knowing how to wink is winking and knowing how to steal a sheep is sheep raiding is to betray as deep a confusion as, taking thin description for thick, to identify winking with eyelid contractions or sheep raiding with chasing woolly animals out of pastures. The cognitivist fallacythat culture consists (to quote a spokesman for the movement...) of "mental phenomena, which can [he means "should"] be analyzed by formal methods similar to those of mathematics and logic"-is as destructive of an effective use of the concept as are the behaviorist and idealist fallacies to which it is a misdrawn correction. (p. 12) 


\section{Clifford Geertz}

The Interpretation of Cultures. New York: Basic Books, 1973.

This quote comes from the dean of interpretive social science, anthropology's Clifford Geertz. Here we see his famous presentation on the wink presentation that is an excellent corrective to empiricists' fantasies about meaning inhabiting or being given in things rather than meaning deriving from intent and from interpretation. Data, in social science, do not 'speak' as it were; they are interpreted and their meanings or significance imposed upon them from assemblages of faith in numbers, social biases, and even anxiety, not spoken from them (see Gilman 1985, 1988; Devereux 1967; Porter 1995). As Geertz noted elsewhere in this project, that a wink, a rehearsed wink, something in one's eye, a flirtatious wink, etc., are all empirically identical. In a clever statement he shows the falsity of assertions of those who believe meaning and intention are irrelevant and can be dispensed with by the use of empirical descriptions and "findings" based on them.

Quote of the Volume

Volume 37: 2013

What people experience and report in connection with their bodies is not in essence the same kind of information produced through observation, measurement, and abstraction. Arbitrary decisions must be made in connection with the creation of scientific standards, scales, and other techniques of measurement. Criteria for inclusion and exclusion have to be set, which in the case of the body are often simultaneously moral decisions about what is normal and abnormal. Sartre highlights an important point that in our eagerness for accuracy, replication, and control we tend to minimize or ignore to our peril: if we are to talk about human beings, and not simply about physiology and biochemistry, then we must resort to other forms of description and analysis. The subjective "me" cannot be replaced by the universal "body," molded and packaged out of the objective language of biology. Nor can it be replaced by the bodies produced as probabilities ( $\mathrm{p}$. xxiii).

Margaret Lock

Scientific Discourse and Aging Women. In: Encounters with Aging. Berkeley: University of California Press, 1993.

Here anthropologist Lock rightly critiques the empiricist view of corporeal reality. The inhabited body is not the biological body seen in tests and examinations with their analogies derived from the cadaveral embrace and biological training of medical education. The personal subject is not to be equated with a non-specific, generic and universal corps. This quote shows western biomedical weltanschauung blinds the physician, as practitioner or researcher, to the individual living person who is neither generic nor universal (Gordon 1988). What is the naturalist view of the body and of disease intends to divorce the viewer (the professional) from the subject to deny illness in the self (Devereux) and confirms the naturalist and 
rationalist weltanschauung, as philosophers of science Charles Taylor and Ian Hacking have noted.

Quote of the Volume

Volume 38: 2014

For a more social orientation in (bio)ethical issues- "If there was some agreement that it would be good to see this kind of inner shift (toward social orientations), not away from philosophy but its incorporation within the framework of more social thinking, you would then have to have training for that. I don't mean that everyone has to run out and get a $\mathrm{PhD}$ in sociology or anthropology, but you just can't do this (a bioethics with social science, ed.) without some training. So, that brings us to the whole business about training programs in bioethics, which is problematic in and of itself because I don't think bioethics is a (single) discipline. "(p. 11)

\section{Renée Fox}

Conversations: Bioethics: Past and Future. Contexts

Summer, 2006.

Sociologist and Bioethicist Renée Fox raises several noteworthy issues. First, that there should be a shift in bioethics toward social and cultural thinking rather than abstract decontextualized ethical thinking. This would include philosophy rather than replace it (or them). The second issue is how the preferred social/cultural training would occur in bioethics programs, especially given the Dr Fox is not sure bioethics is a single discipline. The multiplicity of the endeavor rather than a singularity has been discussed at length by Gaines and Juengst (2008) with the added notion that bioethics, like biomedicine, should be a subject of cultural research.

\section{Quote of the Volume}

Volume 39: 2015

Looked at in this way, the aim of anthropology is the enlargement of the universe of human discourse. That is not, of course, its only aim-instruction, amusement, practical counsel, moral advance, and the discovery of natural order in human behavior are others; nor is anthropology the only discipline which pursues it. But it is an aim to which a semiotic concept of culture is peculiarly well adapted. As interworked systems of construable signs (what, ignoring provincial usages, I would call symbols), culture is not a power, something to which social events, behaviors, institutions, or processes can be causally attributed; it is a context, something within which they can be intelligibly-that is, thickly-described. (p. 14)

\section{Clifford Geertz,}

The Interpretation of Cultures. New York, NY: Basic Books.

In this second Quote of the Volume from Geertz, he points out that culture does not 'cause' events as empiricists, and other causalists, would hope, even demand, as 
if it is a 'real' entity that can make sense of human actions. So here we see that whatever endeavor we are concerned with that considers human belief and action must understand, not explain, the why of such belief and action, for the meaning of acts, including winks and sheep stealing, derives from the cultural context.

Quote of the Volume

Volume 40: 2016

One must ask, why should a discipline (psychiatry) whose roots are so deeply planted in Western culture, whose major figures are almost entirely European and North American (and male), and whose data base is largely limited to the mainstream population in Western societies, why should so strongly Westernoriented a discipline regard cross-cultural research among the more than 80 percent of the world's people who inhabit non-western societies as marginal? Is not cross-cultural research essential to establish the universality of mental illness and international validity of psychiatric categories? Are not comparative studies an antidote to professional ethnocentrism? Can psychiatry be a science if it is limited to middle-class whites in North America, the United Kingdom and Western Europe? (xi-xii)

Arthur Kleinman,

Rethinking Psychiatry: From Cultural Category to Personal Experience. NY: Free Press. 1988.

Psychiatrist/Anthropologist/Sinologist Kleinman points to the severe limitations of Western psychiatry in terms of its practitioners and the populations on whom they practice and theorize.

Here we also note that he points out gender bias in the practice of this science to which we should also add differences in social standing (also see Gaines 1992). Further, psychology as a discipline is poorly aware that its foundational practitioners and subjects in the US were males of a certain class and largely (European) Protestant. Yet psychologists believe themselves, as do psychiatrist, to be engage with and 'explaining' a universal human psychology.

Quote of the Volume

Volume 41: 2017

Realism, like reality, is multiple and evanescent, and no one account of it will do.

Nelson Goodman,

Notes on the Well-Made World, In Of Mind and Other Matters. Nelson Goodman. Cambridge, MA: Harvard University Press, 1987.

Goodman, a philosopher of science and of art (and language) makes the very anthropological point, that that which is thought to be real cannot be elucidated or captured in, or by, a single account (like biology) for there are different realities each of which is multiple and evanescent. In the world of medicine, there is not one biology, but many Local Biologies (Gaines 1987, 2005). It is not that one is an anti- 
realist (see Hacking 1983), but rather one recognizes that there are multiple realities in cultural context.

Quote of the Volume

Volume 42: 2018

Much has been written during the past (four) decades about the social construction of illness. But in an important sense this is no more than a tautology, a specialized restatement of the truism that men and women construct themselves culturally. Every aspect of an individual's identity is constructed-so, also, is disease. Although the social-constructionist position has lost something of its novelty during the (1990s), it has forcefully reminded us that medical thought and practice are rarely free of cultural constraint, even in matters seemingly technical. Explaining sickness is too significant-socially and emotionally-for it to be a value-free enterprise. It is no accident that several generations of anthropologists have assiduously concerned themselves with disease concepts in non-Western cultures, for agreed-upon etiologies at once incorporate and sanction a society's fundamental ways of organizing its world. Medicine in the contemporary West is by no means divorced from such affinities.

Charles Rosenberg

Introduction, Framing Disease: Illness, Society, and History. In Framing Disease. C. Rosenberg and J. Golden, Editors. New Brunswick, NJ: Rutgers University Press 1997.

Noted historian of medicine, Rosenberg, argues for the cultural construction of identity and disease. Diagnosis is not a value free enterprise. Rather such tasks validate views of the world and moral rectitude, as noted in the quote from Lock and others. How we frame disease and establish its geography of affliction has much to do with situated morality and social divisiveness concealed by a naturalist ideology reinforced by a false rationality (Gordon 1988).

\section{Summary}

The quotes presented and briefly commented upon derive from a wide range of seemingly distinct disciplines (sociology, anthropology, medical history, psychiatry, bioethics, philosophy, psychoanalysis, feminist theory). Yet they converge, overlap and support one another as if they were voices from one, unified discipline. Indeed, this is how the author sees them within Millennial Medical Anthropology and CSSM, and its methodology (Cultural Constructivism) (Gaines 1991), and in the Journal Culture, Medicine and Psychiatry itself. 


\section{References}

Devereux, George

1967 From Anxiety to Method in the Behavioral Sciences. The Hague, Netherlands: Mouton.

Gaines, Atwood D.

1987 Cultures, Biologies and Dysphorias. Transcultural Psychiatric Research Review 24(1):31-57.

1991 Cultural Constructivism: Sickness Histories and the Understanding of Ethnomedicines Beyond Critical Medical Anthropologies. In Anthropologies of Medicine: A Colloquium on West European and North American Perspectives. Beatrix Pfleiderer and Gilles Bibeau, eds. Wiesbaden, Germany: Vieweg und Sohn Verlag.

1992 From DSM 1 to III-R: Voices of Self Mastery and the Other: A Cultural Constructivist Reading of US Psychiatric Classification. Social Science and Medicine 35(1):3-24.

2005 Race: Local Biology and Culture in Mind. In Companion to Psychological Anthropology: Modernity and Psychocultural Change. Conerly Casey and Robert B. Edgerton, eds., pp. 255278. Oxford: Blackwell.

2010 Millennial Medical Anthropology: From There to Here and Beyond, or the Problem of Global Health. Culture, Medicine and Psychiatry 35(1):83-89.

Gaines, Atwood D., and Eric Juengst

2008 Origin Myths in Bioethics: Constructing Sources, Motives and Reason in Bioethic(s). Culture, Medicine and Psychiatry 32:303-327.

Gilman, Sander

1985 Difference and Pathology. Ithaca, NY: Cornell University Press.

1988 Disease and Representation. Ithaca, NY: Cornell University Press.

Gordon, Deborah

1988 Tenacious Assumptions in Western Medicine. In Biomedicine Examined. M. Lock and S. Lindenbaum, eds. Dordrecht, The Netherlands: D. Riedel.

Hacking, Ian

1983 Representing and Intervening: Introductory Topics in the Philosophy of Natural Science. Cambridge: Cambridge University Press.

Porter, Theodore M.

1995 Cultures of Objectivity. In Trust in Numbers: The Pursuit of Objectivity in Science and Public Life. T. Porter, ed. Princeton, NJ: Princeton University Press.

Rabinow, Paul, and William M. Sullivan

1979 Interpretive Social Science: A Second Look. Berkeley, CA: University of California Press. 